\title{
Nerve transfers for severe brachial plexus injuries: a review
}

\author{
RAJIV MidHa, M.D., MSc., F.R.C.S.(C) \\ Division of Neurosurgery, Department of Surgery, Sunnybrook and Women's College Health Sciences \\ Centre, University of Toronto, Ontario, Canada
}

\begin{abstract}
Nerve transfer procedures are increasingly performed for repair of severe brachial plexus injury (BPI), in which the proximal spinal nerve roots have been avulsed from the spinal cord. The procedure essentially involves the coaption of a proximal foreign nerve to the distal denervated nerve to reinnervate the latter by the donated axons. Cortical plasticity appears to play an important physiological role in the functional recovery of the reinnervated muscles. The author describes the general principles governing the successful use of nerve transfers. One major goal of this literature review is to provide a comprehensive survey on the numerous intra- and extraplexal nerves that have been used in transfer procedures to repair the brachial plexus. Thus, an emphasis on clinical outcomes is provided throughout. The second major goal is to discuss the role of candidate nerves for transfers in the surgical management of the common severe brachial plexus problems encountered clinically. It is hoped that this review will provide the treating surgeon with an updated list, indications, and expected outcomes involving nerve transfer operations for severe BPIs.
\end{abstract}

KEY WoRDS $\bullet$ brachial plexus injury $\quad$ nerve transfer $\quad$ neurotization $\bullet$
accessory nerve $\quad \bullet \quad$ C-7 spinal nerve $\bullet$ intercostal nerve $\quad$ medial pectoral nerve

Nerve transfers (so-called neurotization) involve the repair of a distal denervated nerve element by using a proximal foreign nerve as the donor of neurons and their axons to reinnervate the distal targets. The concept is to sacrifice the function of a lesser-valued donor muscle to revive function in the recipient nerve and muscle that will undergo reinnervation..$^{71}$ The first report of neurotization in an attempt to restore injured plexus function was published by Tuttle ${ }^{100}$ in 1913. A review of the historical precedents as well as the anatomical basis and rationale for nerve transfers in brachial plexus surgery was most clearly presented 20 years ago by Narakas. ${ }^{70}$ Since then, nerve transfers have become increasingly popular and used for the repair of BPIs, especially in cases in which the proximal motor source of the denervated element is absent due to avulsion from the spinal cord ${ }^{88}$ Increasingly advocated as well is the use of nerve transfers in cases in which the proximal motor source is available but the distance between removal and reimplantation is so long that the outcome would be poor; ${ }^{30,31}$ a nerve transfer into the denervated distal nerve stump close to the motor end organ would then restore function, which otherwise would not be possible. ${ }^{72}$ The use of nerve transfers has been a major advance in the field of brachial plexus nerve reconstructive surgery, with many different ingenious transfers associated with improving results, as reported and reviewed recently. ${ }^{11,43,64,88,98}$

Abbreviations used in this paper: BPI = brachial plexus injury; MRC $=$ Medical Research Council.
The anatomical and physiological principles that underlie nerve transfers are relatively straightforward. Because motor recovery has been the main goal, the choice of a donor nerve element with a reasonable amount of motor fibers is required. ${ }^{71}$ The loss of the muscle due to denervation when transferring the donor nerve must not represent loss of important or critical function..$^{55}$ Obviously, the value of the neuromuscular element to be reinnervated must greatly exceed the utility of the sacrificed one. An excellent compromise is achieved if some function of the donor muscle can be retained, by using only a portion of the nerve as the donor, which has been exemplified by the use of half of the hypoglossal nerve (thus, not completely denervating ipsilateral tongue) for transfer to the facial nerve for reanimation of the face. . $^{622,28,83}$

There are several important principles to adopt to maximize outcome in nerve transfers, the first of which is to reinnervate the recipient nerve as close to the target muscle as possible. ${ }^{72}$ An outstanding example of the latter is the transfer of an ulnar nerve fascicle directly to the biceps branch of the musculocutanoeus structure in close proximity to its entry into the muscle. ${ }^{74}$ The second principle involves performing a direct repair, without intervening grafts; this tactic seems to be associated with improved outcomes, as reported convincingly after intercostal-musculocutaneous transfers. ${ }^{45,58,69,76,103}$ The third principle is to use combinations of similarly behaving neuromuscular units, maximized when agonistic donor and recipient are chosen, as cortical readaptation is the physiological basis for functional recovery. ${ }^{56,59}$ This may also be the physio- 
logical underpinning that explains why intraplexal (for example, medial pectoral-musculocutaneous) nerve donors may yield superior results compared with extraplexal (for example, intercostal-musculocutaneous) nerves. ${ }^{79}$ The last principle, not so different from that in all nerve surgery (assuming that the nerve is irreparably damaged and incapable of spontaneous functional regeneration ${ }^{66}$ in which prolonging axotomy and target denervation is associated with progressively poorer outcomes, ${ }^{30,31}$ is to perform the transfer surgery as early as possible to maximize outcomes. ${ }^{80,81}$

\section{NERVE TRANSFER TECHNIQUES}

\section{Surgical Approach}

The surgical management of patients with a severe BPI is first to determine preoperatively whether most or all the nerve roots are truly avulsed. ${ }^{65}$ The second aspect of surgery is to perform nerve repair, which, in the severe cases with avulsion, incorporates appropriate nerve transfers to reanimate the extremity. ${ }^{88}$ Surgical exploration therefore warrants exposure of the entire supra- and infraclavicular plexus, with an appropriately made incision, as well as marking of incisions that will allow exposure of donor nerves that may need to be transferred (Fig. 1). The upper extremity, extending to the anterior and lateral chest wall, and both legs being targeted for donor sural grafts, should be appropriately prepared.

After complete and thorough exposure of the plexus, including intraforaminal dissection and external neurolysis of the nerve-in-continuity, intraoperative electrodiagnostic studies should be conducted ${ }^{66}$ First, motor evoked stimulation is used to determine which roots are conducting by observing the distal muscles contraction, occasionally augmented by needle-based electromyography. Nerve action potentials are measured across the neuroma or in clinically nonfunctioning roots, with large fast-conducting (preganglionic) nerve action potentials seen when the nerve root is avulsed. ${ }^{49,51,66,97}$ Somatosensory evoked potentials produced in the contralateral cortex help gauge

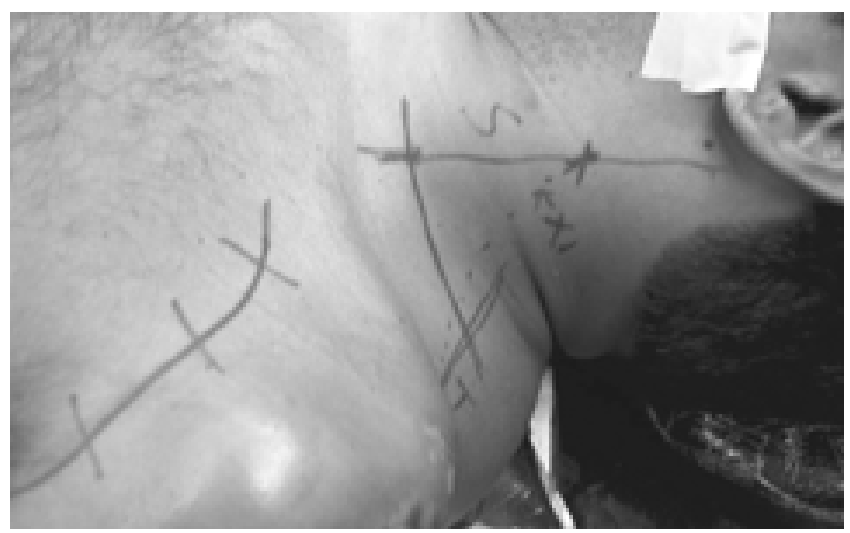

Fig. 1. Photograph showing incisions to expose various plexal and extraplexal donor and recipient nerve elements. This patient suffered clinically complete Erb palsy and avulsion of C-5 and C6 spinal nerves; he underwent surgery after a delayed referral (the same patient is represented in Figs. 6 and 7). the integrity of sensory roots but do not reflect the status of the motor (ventral) roots, which can be measured using motor evoked potential and/or neck muscle potential monitoring. ${ }^{15,73}$ The intraoperative electrical tests and operative findings are used in concert with the preoperative clinical, electromyography, ${ }^{9}$ and imaging ${ }^{16}$ findings to determine the extent of injury and presence of nerve root avulsion and to guide operative decisions concerning the suitable nerve reconstructive procedure.

The goal in the management of upper (C-5 and C-6) nerve root paralysis is complete repair. When the upper two roots are avulsed from the spinal cord, the only repair option is neurotization by a nerve transfer. The nature of the reparative strategy is then dictated by the number of root avulsions, including the consideration of whether $\mathrm{C}$ 7 is also avulsed. On the other hand, even in complete severe palsy, the C-5 spinal nerve may be singularly spared, thus allowing it to be used as the source of axons for a plexus-plexus repair to distal elements. ${ }^{34,47}$ There are some cases in which the proximal root stump may not be suitable for grafting. A very proximal intraforaminal dissection of the nerve roots is invaluable for assessing the nerve anatomically, ${ }^{48}$ and combined with the examination of frozen section of the very proximal stump to assess the fascicular pattern and absence of ganglion cells, has been useful in decision making. Other authors have assessed the degree of myelin staining to predict the quality of the stump; ${ }^{61}$ however, in uncertain circumstances, a nerve transfer is preferred to using a proximal stump of questionable integrity. The combinations for repair therefore include intraplexal grafts alone obtained from a single functioning root, intraplexal grafts, and selective transfers (the usual scenario) or transfers alone for the devastating cases in which all nerve roots are avulsed (Fig. 1). The nerve transfer options available will be discussed further.

\section{Accessory Nerve Transfer}

In the earliest report of a nerve transfer by Tuttle ${ }^{100}$ in 1913, the author mentioned using the accessory nerve (as well as elements of the cervical plexus) as the donor. Accessory (11th cranial) nerve transfers for otherwise irreparable BPIs, however, were popularized independently in the early 1980 s by Allieu, et al., ${ }^{3,4}$ and others. ${ }^{5,71}$ In the early series, a diverse number of recipient targets were chosen, and, depending on the distal nerve element, interposed grafts were often needed. Based on cadaveric studies, ${ }^{46}$ an improved appreciation of the extracranial accessory nerve's anatomy has led to the use of more distal dissection of the nerve close to trapezius muscle insertional points, where the very distal nerve is divided prior to its transfer. ${ }^{41}$ This preserves some trapezius innervation and allows a direct transfer to the adjacent suprascapular nerve, without the need for an interpositional graft (Fig. 2).

For restoration of dynamic shoulder function, both the suprascapular and axillary nerves have been chosen as targets. Whereas the former can be repaired directly by endto-end suture with the distal accessory nerve, the latter requires planning an interposed nerve graft. The authors of recent series have confirmed Alnot's bias ${ }^{5}$ that the suprascapular, compared with axillary, nerve is a superior target for accessory nerve transfer, with generally good 


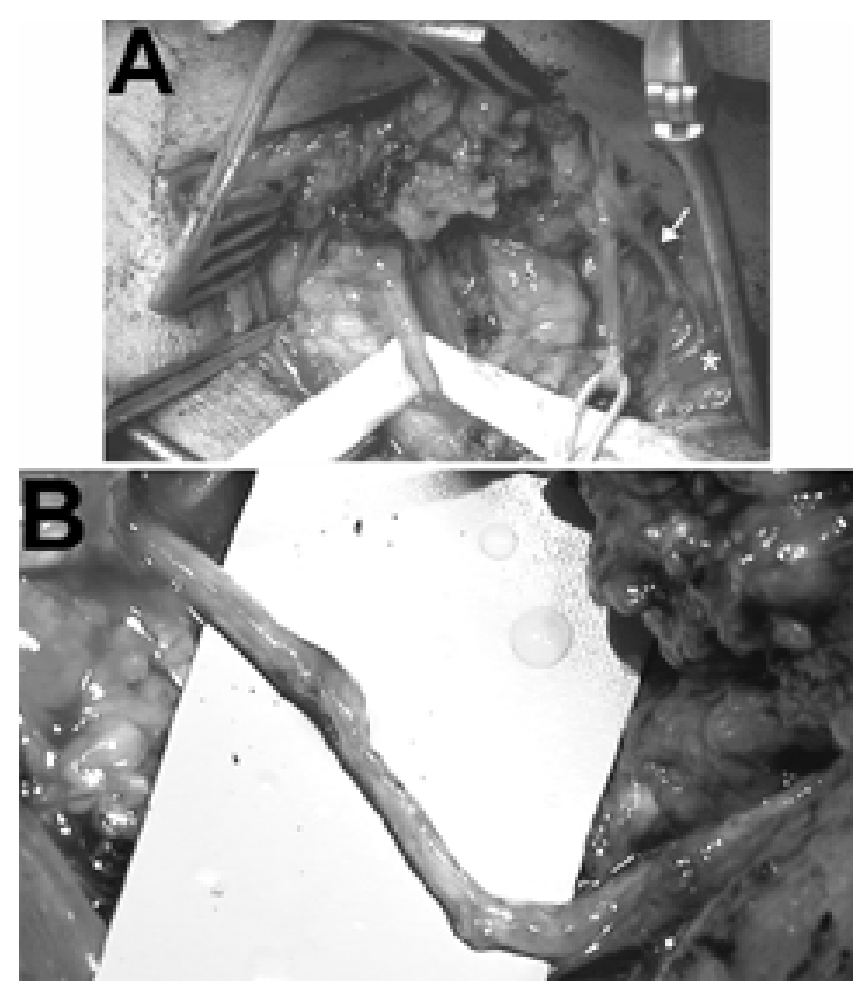

Fig. 2. Intraoperative photographs. A: A transverse incision 1 $\mathrm{cm}$ superior to left clavicle allows simultaneous exposure of the suprascapular nerve (Penrose drain), just after its origin from the upper trunk and accessory nerve (vessel loop) distal to branches of the latter (arrow) to trapezius muscle (asterisk). B: Direct transfer of the distal accessory to the suprascapular nerve with microsurgical repair.

results reported in the majority of patients (Fig. 3)..$^{19,40,77}$ A detailed analysis of glenohumeral function in patients with long-term follow up who underwent accessory nerve-suprascapular nerve transfer, however, has demonstrated rather poor true abduction (Malessy, personal communication), supporting the observation that shoulder function will be optimized if both suprascapular and axillary nerves and their muscles are reinnervated. ${ }^{79}$ In a recent metaanalysis of the literature related to nerve trans-

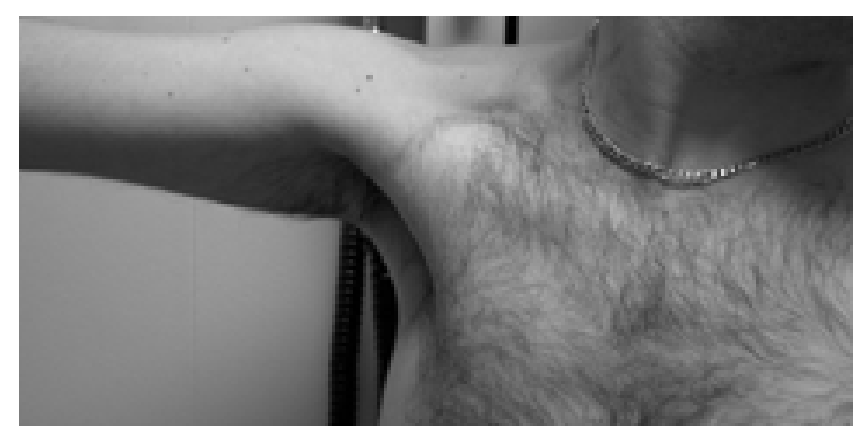

Fig. 3. Photograph obtained at 3-year follow-up visit. This patient experienced excellent outcome after undergoing an accessory-suprascapular nerve transfer to treat clinically complete Erb palsy and C5-7 nerve avulsions. fers, Merrell, et al. ${ }^{64}$ concluded that best results for shoulder abduction were achieved by conducting accessory nerve-suprascapular nerve transfers.

The other major target for accessory nerve transfer has been the musculocutaneous nerve. In recent series the results for elbow flexion were shown to be very good, with an MRC Grade 3 or better outcome in $65 \%, 7972 \%, 80$ $72.5 \%,{ }^{89}$ and $83 \%{ }^{103}$ of patients in respective studies. In the analysis of factors predicting outcome, the most important negative predictor was increased duration between injury and surgery, whereas the need for a lengthier graft also negatively influenced results. ${ }^{80,103}$ Although a metaanalysis of the literature has indicated that intercostal nerve donors are best for musculocutaneous nerve as the recipient nerve, ${ }^{64}$ only Waikakul, et al. ${ }^{103}$ directly compared two extraplexal donors, reporting that the accessory nerve achieved superior outcomes for elbow flexion compared with intercostal nerves.

\section{Intercostal Nerve Transfers}

The concept for intercostal nerve transfers to repair BPIs can be credited according to Narakas, ${ }^{70}$ to Yeoman, working with Seddon, and Seddon; ${ }^{84}$ this early experience is reviewed in the latter's classic textbook. Although Seddon reported the use of the second-fourth intercostal nerve transfer to the distal musculocutaneous nerve, Dolenc ${ }^{24}$ performed multiple intercostal transfers to several additional distal elements of the plexus, including axillary, median, and radial nerves. He used sural and ulnar nerves as interposed grafts and reported considerable success, although few details were provided. ${ }^{24}$ Subsequently, several other surgeons independently adopted this technique for reinnervation of the musculocutaneous nerve but with variable success. ${ }^{45,67,68,71,85-87}$

Friedman and colleagues ${ }^{29}$ used standardized techniques involving transfer of three intercostal nerves (third-fifth) to the distal musculocutaneous nerve, without interposed grafts, which led to more consistent results, approaching MRC Grade 3 or better function in approximately $50 \%$ of the patients. These authors provided the first detailed evidence of independent (that is, without synkinetic respiratory movements) biceps function over time, hinting at cortical plasticity, a concept that has subsequently been validated by electrophysiological and functional brain mapping/imaging studies. ${ }^{56,59,60,62}$ Indeed, it has been suggested that functional return depends on cortical readaptation and that failures have been construed as lack of such adaptation; $;{ }^{56}$ this hypothesis, however, requires validation.

More recently investigators studying intercostal-musculocutaneous nerve transfer have demonstrated significantly improved results, (MRC grade $\geq 3$ elbow flexion in $64-88 \%$ of reported cases). ${ }^{26,45,58,69,76,88,103}$ Intercostal nerve transfers to musculocutaneous nerves in infants with obstetrical brachial plexus palsy produced reliably good outcomes (MRC grade $\geq 4$ elbow flexion in nearly $85 \%$ of patients). ${ }^{44}$ The authors of these recent series have stressed the importance of dissecting the intercostal nerves well distally along the rib to allow their transfer easily to the axilla and direct repair without graft placement, as has been demonstrated in anatomical studies (Fig. 4). ${ }^{7}$

The group from Duke University has also reported, in 


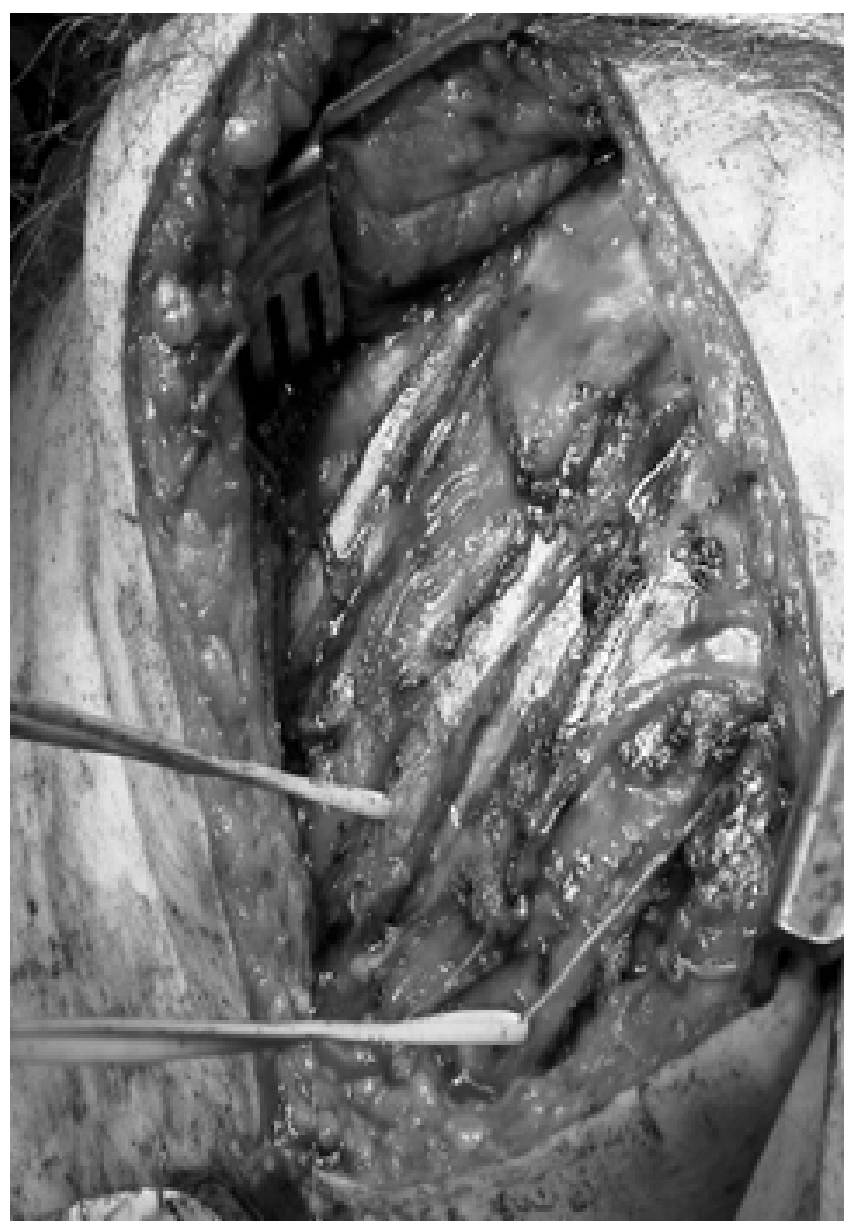

Fig. 4. Intraoperative photograph depicting a curvilinear incision lateral to nipple (upper-left region in photograph) and just anterior to anterior axillary line; this allows exposure of the left third-fifth intercostal nerves for transfer to the musculocutaneous nerve in the axilla.

selected cases, intercostal neurotization of nerve to a free muscle graft that successfully achieved elbow flexion. ${ }^{29}$ Although Waikakul, et al., ${ }^{103}$ have reported superior results when using accessory nerve, compared with intercostal transfers for elbow flexion, the authors of a large series of 37 adolescents and adults who underwent placement of gracilis muscle grafts for elbow flexion found that intercostal neurotization of nerve to free muscle was a better choice than using the accessory nerve. ${ }^{21}$ In severe obstetrical brachial plexus palsy, a gracilis free muscle transfer (innervated by the accessory nerve) has been shown to restore elbow flexion. ${ }^{10}$ Doi and colleagues ${ }^{23}$ have reported a two-stage ("double") free muscle transfer procedure that successfully restored prehensile function in a few very severe cases.

Unilateral intercostal nerve transfers do not disturb respiratory function, ${ }^{32}$ but they should not be performed if the phrenic nerve is dysfunctional or used on the ipsilateral side as a donor for transfer. ${ }^{55}$

\section{Ipsilateral and Contralateral C-7 Spinal Nerve Transfer}

In some cases of Erb palsy, ${ }^{27}$ in which both C-5 and C6 nerves are avulsed, the C-7 spinal nerve is intact and available as an intraplexal donor for reinnervating the distal upper truncal or its divisional outflow. ${ }^{47,50,95}$ Such a transfer can be associated with very good outcomes in terms of recipient elements, ${ }^{47,95,96}$ with little risk of functional loss secondary to harvesting the C-7 spinal nerve. ${ }^{36}$ Considerable caution, however, is required if significant lower plexus lesions coexist ${ }^{36}$ because the muscles innervated by $\mathrm{C}-7$, which would be normally redundantly supplied by C-8 (and T-1) spinal nerves, will not be present. ${ }^{50}$

The use of the contralateral C-7 spinal nerve as donor for transfer has corroborated the redundancy of the C-7 nerve, confirming the safety of sacrificing this structure. ${ }^{18,95}$ Other than mild loss of triceps function and clinically inconsequential loss of the triceps reflex, the procedure appears to be safe as far as motor loss is concerned. ${ }^{18,95}$ Sensory abnormalities, however, are common after C-7 sacrifice and may be permanent in 5\% of cases. ${ }^{92}$ Moreover, neuropathic pain may be evoked temporarily in a minority of patients, ${ }^{2}$ and in rare cases permanent motor deficits in wrist extension may develop..$^{90}$ Selective use of anterior or posterior portions of the contralateral C-7 nerve, aided by intraoperative electrophysiological testing,$^{42}$ may make the procedure safer, furthering the specificity of the reinnervated element to which it is transferred..$^{5}$

Chuang and colleagues ${ }^{20}$ first reported the use of the contralateral C-7 spinal nerve obtained from the normal, noninjured side, where the first stage involved the repair to the C-7 nerve and placement of long sural nerve grafts across the chest. In their initial series of 15 patients, eight were candidates for the second stage ( 1 year later) consisting of innervation of free muscle grafts placed in the affected paralyzed limbs. They reported modest results of nonindependent movement in the paralyzed limb in this pioneering effort, attesting to both the possibility but also limitations of the technique. Authors of subsequent series in adolescents and adults reported the results of contralateral C-7 transfer by grafting cross-chest sural or vascularized ulnar nerve directly to recipient infraclavicular plexal nerve elements. $18,35,37,95,96,102,107$ In the largest reported series, the long-term functional outcome was very good, but the authors only reported data obtained in 20 of 82 patients in their initial study and 30 of 224 patients who underwent the procedure. ${ }^{35,37}$ Additionally, synchronous movement of the unaffected arm during attempts to move the reinnervated limb have been a repeated concern. ${ }^{35}$ The best results associated with using the contralateral C-7 nerve in 98 adolescents and adults with complete avulsion injuries were published by Waikakul and colleagues; ${ }^{102}$ they noted that when the median nerve was the recipient, good sensory function was achieved in approximately half the adolescents, and some also exhibited forearm muscle recovery. In a carefully reported 3-year follow-up study, Songcharoen and associates ${ }^{90}$ reported median nerve motor recovery (MRC Grade 3 or 4) in approximately $20 \%$ of their patients, whereas in another $20 \%$ MRC Grade 2 outcome in wrist flexion was observed. Sensory domain outcome was somewhat better, especially in adolescents, with $50 \%$ exhibiting useful sensory restoration in the median nerve distribution. In study of adults with BPIs, Terzis and coworkers ${ }^{96}$ reported that the mean MRC grade was 3 (antigravity) in their series. One group transferred C-7 spinal nerves via vascularized ulnar nerve graft, to the 
lateral cord contribution to median nerve; they reported a $100 \%$ success rate with good sensory recovery. ${ }^{26}$

One of the main criticisms of this transfer technique remains the long graft (and hence regeneration) distance. The possibility of a prespinal retropharyngeal route for graft placement has been proposed. ${ }^{63}$ Nevertheless, the technique remains limited because of the rather modest motor recovery, the fact that synchronous movement of the unaffected side is required, and the small but real risk that the donor site may be injured and a functional deficit results. ${ }^{90,92}$ Perhaps a targeted approach to obtaining median nerve distribution sensory recovery is warranted, ${ }^{26}$ although similar outcomes may be possible with a less cumbersome transfer from the lower intercostal nerves to the sensory (lateral cord) head of the median nerve. ${ }^{24}$

\section{Cervical Plexus}

The use of the anterior branches of the cervical plexus (C-3 and C-4) for transfer to the distal elements usually supplied by (the avulsed) upper spinal nerves was first advocated by Brunelli and Monini. ${ }^{14}$ Based on cadaveric studies in which they observed present (but variablesized) discernible sensory and motor branches, the authors reported modest results after selective transfer of motor branches to musculocutaneous, suprascapular, and axillary nerves and sensory branches to the median nerve. Earlier efforts to transfer the entire cervical plexus elements to the avulsed C-5 and C-6 roots failed, likely because of the great disparity between the number of axons in the donor cervical plexus elements and the recipient elements. ${ }^{14}$ Recently, however, Yamada and colleagues ${ }^{106}$ performed surgery in three cases in which they transferred the anterior primary rami of C-3 and C- 4 , just distal to phrenic nerve, via sural nerve grafts directly to the upper trunk; the patients had suffered C-5 and C- 6 avulsion injuries, and the authors reported good results postoperatively in shoulder girdle and biceps muscles, as well as improved sensation. In a larger series, they obtained even better results in cases involving upper plexus palsy and, surprisingly, in cases involving complete flail arm. ${ }^{105}$ Other investigators have been unable to validate these remarkable results, demonstrating more modest success when using the motor components (which are unfortunately quite limited after phrenic nerve supply ${ }^{14}$ ) to branches of the upper trunk when both C-5 and C- 6 nerves are avulsed. ${ }^{25,47,50}$

\section{Phrenic Nerve}

Unlike the cervical plexus, which contains a variable number of motor fibers, ${ }^{14}$ the phrenic nerve contains a large number of pure motor axons that allow the possibility of entire or partial transfer with success. ${ }^{101}$ In the early use of the phrenic nerve for transfer, investigators noted good outcomes..$^{17,101}$ Subsequently, transfers involving the phrenic nerve as the neurotizer have been performed with considerable success. $17,19,38,43,101,107$ In one study of 12 patients, phrenic nerve transfer to musculocutaneous, suprascapular, or axillary nerves was successful in $75 \%$ of cases. ${ }^{88}$ Particularly, the transfer to the musculocutaneous nerve has been an excellent tactic, with 11 of 12 patients exhibiting better than antigravity function (MRC Grade 3) and 58\% exhibited MRC Grade 4 function. ${ }^{55}$ One group, however, noted that in their hands, a portion of the median nerve was a more reliable donor for achieving elbow flexion recovery than the phrenic nerve. ${ }^{43}$ When the phrenic nerve is sacrificed, one important issue is the resulting respiratory compromise, in which decrease in vital capacity has been measured to be a mean of approximately $10 \% .{ }^{55}$ Although not clinically important in the majority of situations, this degree of respiratory loss will produce symptoms in higher-demand situations and may be severely detrimental to infants and children who develop respiratory infections. This factor essentially precludes the use of the phrenic nerve as a donor in infants undergoing nerve reconstruction for obstetric palsy. Moreover, it also implies that the intercostal nerves should not be used as donors for transfer when phrenic nerve function is absent preoperatively or when the phrenic nerve is transferred.

\section{Medial Pectoral Nerves}

The pectoralis major muscle has dual input from the medial and lateral pectoral nerves, arising from the medial and lateral cords, respectively. Because C-5 and C- 6 avulsion interrupts the lateral cord supply, the muscle remains innervated (and strong) as long a significant injury is not incurred to the C-7 and C-8 elements. Although popularized recently for upper plexal injuries, ${ }^{13}$ using the medial pectoral nerve as a donor for transfer was previously considered and infrequently used, as indicated by Narakas $^{70}$ for adults and Gilbert ${ }^{33}$ for obstetric palsy. Brandt and Mackinnon ${ }^{13}$ directed the medial pectoral to the musculocutaneous nerve, with the additional innovation of turning the lateral antebrachial cutaneous nerve (the cutaneous derivative of the musculocutaneous nerve) into the biceps muscle to avoid loss of motor axons into the cutaneous distribution. A resurgence of interest in this transfer has been associated with reports of useful outcomes (defined as MRC grade $\geq 3$ ) in elbow flexion in approximately $84 \%$ of patients. ${ }^{78}$ Excellent results in obstetric palsy too have been published, with success in $68 \%$ of cases. ${ }^{12}$ Others have criticized the use of this transfer strategy in obstetric palsy because of loss of arm adduction, which can be useful for the infant, toddler, and child to hold objects against the trunk, ${ }^{59}$ especially because the intercostal transfer yields such favorable results in this setting. ${ }^{44}$ The results of various series vary, however, and Samardzic, et al., ${ }^{79}$ have noted that medial pectoral nerve transfers were associated with significantly improved outcomes in elbow flexion compared with intercostal and accessory nerve transfers. These authors have also been one of the few groups to demonstrate remarkably good results after axillary nerve transfer; they observed useful results in greater than $80 \%$ of patients. ${ }^{78}$

With the increasing interest in the medial pectoral nerve as a donor, the anatomy of the pectoral nerve complex has been more clearly defined. ${ }^{8,39}$ The traditional concept of separate lateral and medial pectoral nerves innervating the pectoralis minor and major muscles as discrete nerves has been replaced; in fact, these nerves run toward the pectoralis minor and major muscles, exhibiting considerable branching and intermingling. Not infrequently, a plexus forms where branches from the medial and lateral pectoral nerves, destined for the pectoralis major, merge and then final branches move toward the muscle (Fig. 5A). ${ }^{8,39} \mathrm{Be}-$ 
cause only one or, at times, two of these terminal branches to the pectoralis are required (and quite distally) for the transfer, the practical implication is that some pectoralis major muscle supply can be preserved and a direct repair without intervening graft can be performed to the musculocutaneous nerve in the distal axilla (Fig. 5B). ${ }^{72}$ Caution needs to be exercised if C-7 and C8 nerves are significantly injured; in this case, the pectoralis major muscle will be quite weak preoperatively, and this finding is a contraindication to medial pectoral transfer. A similar sophisticated appreciation of the innervated anatomy to the biceps and brachialis muscles ${ }^{93}$ has prompted evolution in transfer techniques so that both the biceps and brachialis muscles discretely become reinnervated. ${ }^{99}$

\section{Distal Interplexal Transfer}

An exciting development in neurotization has been the transfer of portions of functioning distal plexal elements for the direct reinnervation of nerve branches going to critical muscles that are paralyzed..$^{72}$ This era really began recently with anatomical studies of the fascicular patterns and their application in several patients in whom a single redundant ulnar nerve fascicle was transferred to biceps branches in the medial arm to restore elbow flexion (Fig. 6). ${ }^{74}$ These initial excellent results were validated by sev-

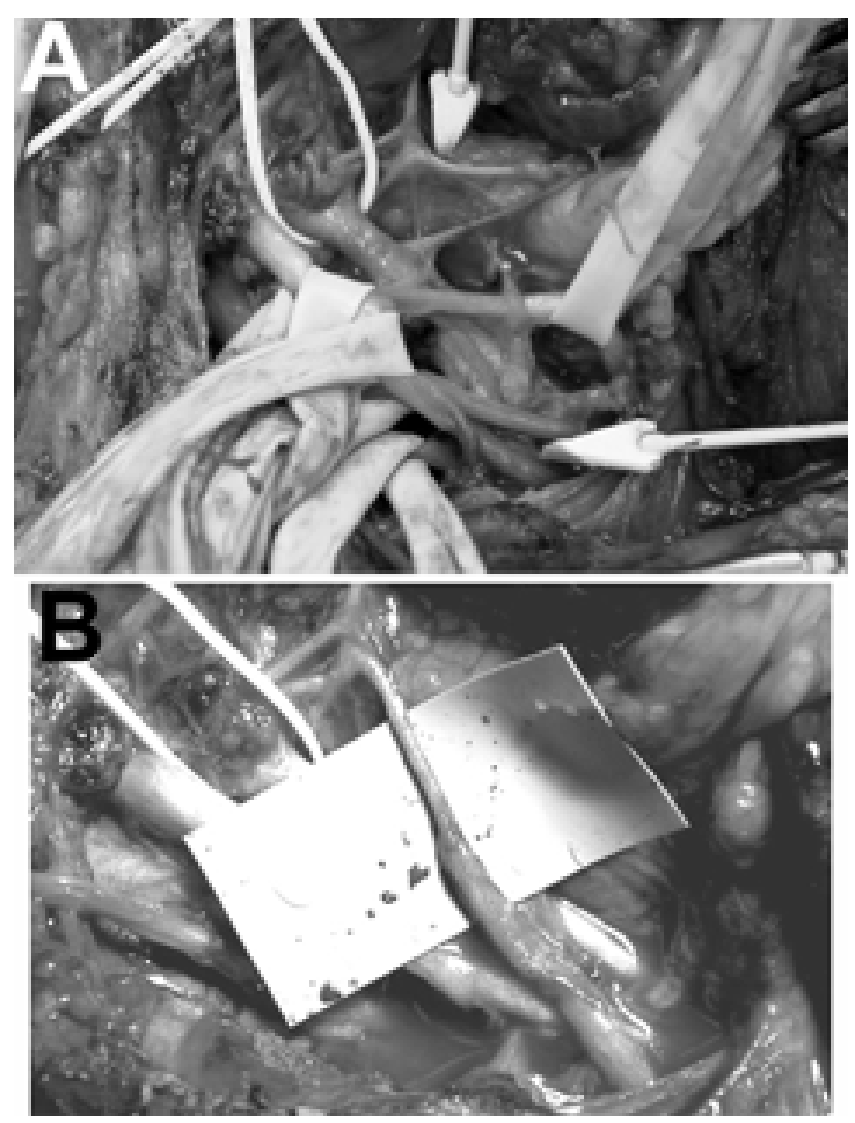

Fig. 5. Intraoperative photographs. A: Pectoral nerves and their complex (upper spear) as well as the musculocutaneous nerve (lower spear) in the axilla are exposed. B: Distal division of the pectoral nerve close to muscle and proximal division of the musculocutaneous nerve allow direct end-to-end repair. eral authors. ${ }^{1,43,52,54,74,94}$ Most impressive have been the results reported by Sungpet and associates ${ }^{94}$ who used a single ulnar nerve fascicle directed to the biceps muscle; they observed MRC Grade 3 or better outcome in 34 of 36 patients. They also noted that time to reinnervation began as early as 3.3 months postoperatively and that hand and ulnar function, assessed using a series of tests and functional tools, was not compromised during a long-term follow-up period. The key aspect of the procedure is to reinnervate the biceps branch close to its motor entry into the muscle. ${ }^{93}$

The authors of a recent report indicated that elbow flexion function will be further augmented (especially in cases of delayed surgery) by also concomitantly reinnervating brachialis muscle by using a graft from the medial pectoral nerve. ${ }^{99}$ Another alternative to the ulnar fascicle is a fascicle of the adjacent median nerve to transfer to biceps muscle nerve; good results have been reported in $64 \%{ }^{43}$ to $80 \%$ of patients. ${ }^{91}$

An emerging transfer technique is the direct repair of the anterior branch of the axillary nerve; in this procedure, the nerve to the long head of triceps in the posterior arm is used (Fig. 7). ${ }^{53,104}$ The anatomy involved in this transfer operation ${ }^{104}$ as well as good-to-excellent results achieved in seven cases,${ }^{53}$ especially when combined with accessory-suprascapular nerve transfer, may herald improved dynamic shoulder function than previously possible with the flail shoulder after C-5 and C-6 avulsions..$^{53}$ Indeed, authors of the most recent series have demonstrated the benefit of several targeted transfers in patients with plexus avulsions. ${ }^{11}$

\section{Other Transfers}

Although the hypoglossal nerve has been an excellent donor for transfer to the facial nerve, ${ }^{75,82}$ it has an extremely limited value for neurotization of brachial plexus elements. ${ }^{28,57}$

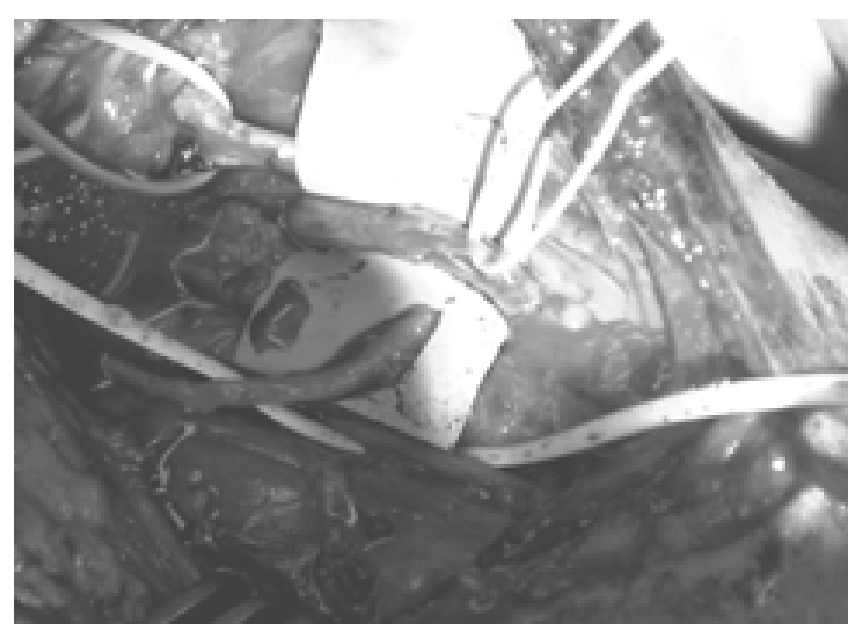

Fig. 6. Intraoperative photograph. For transfer of an ulnar nerve fascicle to biceps nerve in the medial arm, the common epineurium of the ulnar nerve is opened under microscopic magnification; four to five fascicles and a redundant fascicle (vessel loop) are chosen to transfer directly to the adjacent biceps nerve branch of musculocutaneous nerve (both on tissue background). 


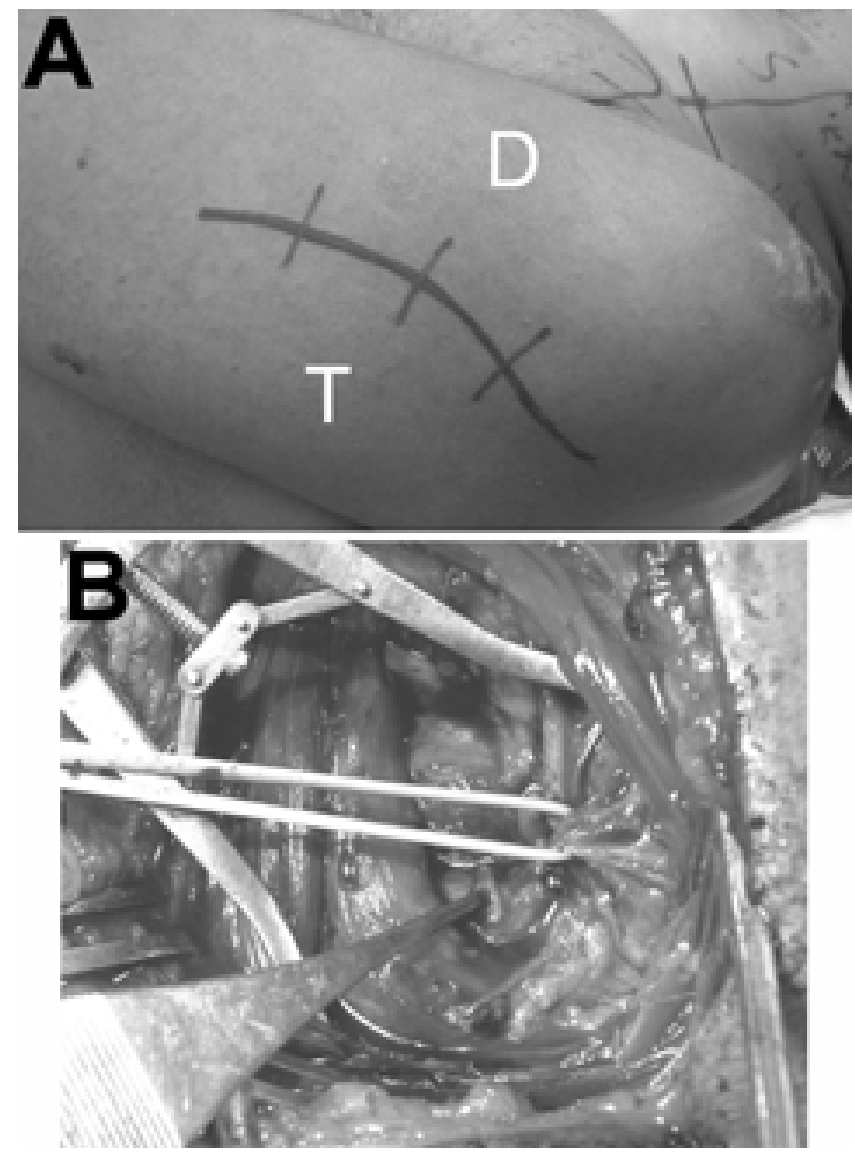

Fig. 7. A posterior arm incision (A) between the posterior border of the (denervated) deltoid (D) and the triceps (T) muscles allows exposure of the axillary nerve (B) in the quadrilateral space (vessel loop), as well as the radial nerve and the nerve to the long head of the triceps muscle (forceps) in the triangular space. Transfer of the latter to the anterior branch of the distal axillary nerve is easily accomplished for direct repair, without tension.

\section{Choosing a Nerve Transfer Technique}

Much of the literature related to brachial plexus surgery comprises retrospective case reviews, anecdotal experience, a small number of prospective studies, and no randomized studies involving different surgical techniques. Moreover, the field has been in flux, with traditional plexus-plexus repairs ${ }^{47,50}$ gradually being replaced by a much more liberal use of nerve transfers. . $^{11,43,64,88,98}$ Thus, evidence concerning the best technique for a particular lesion is limited; however, based on recent review findings, in addition to those presented here and reported elsewhere, ${ }^{64}$ certain general guidelines can be provided.

After conducting a metaanalysis of literature involving nerve transfers, some authors noted that shoulder abduction is best restored by an accessory nerve transfer to the suprascapular nerve, whereas elbow flexion is best regained using intercostal nerves without grafts. ${ }^{64}$ In the grim scenario of complete avulsion, the addition of a contralateral C-7 transfer with an interposed vascularized ulnar nerve graft directed to the entire, or perhaps, lateral root of median nerve in the axilla can be considered..$^{96}$ Alternatively, some lower intercostal nerves or cervical plexus elements can be directed to the sensory aspect of the median nerve. These transfer strategies are certainly appropriate for cases in which a complete flail arm is exhibited with all five spinal nerve roots avulsed; however, it is most important in this case to ensure that the C-5 spinal nerve is in fact avulsed and not ruptured extraforaminally. ${ }^{48}$ Not to perform intraplexal repair of an intact C-5 spinal nerve to its distal outflow would be a disservice because of the relatively few extraplexal transfer possibilities available. In uncertain cases, the repair from C-5 to distal elements can be augmented by the transfer of accessory and intercostal nerves. ${ }^{47}$

Although the aforementioned strategy is appropriate for the pan-plexus injury, treatment of isolated Erb palsy is different. If C-5 and C-6 are avulsed while C-7 is clearly intact, intraplexal graft repairs from $\mathrm{C}-7$ may be considered to reinnervate the shoulder abductors and elbow flexors. ${ }^{47}$ Alternatively, directed discrete transfers should be performed; based on the most recent literature, this seems to be a favored approach. A combination of the following should be performed: distal accessory to suprascapular; ulnar nerve fascicle to biceps nerve (perhaps augmented by a portion of medial pectoral nerve via graft to brachialis nerve); and long head of triceps nerve to the anterior portion of the axillary nerve. ${ }^{11}$

\section{References}

1. Al-Qattan MM: Oberlin's ulnar nerve transfer to the biceps nerve in Erb's birth palsy. Plast Reconstr Surg 109:405-407, 2002

2. Ali Z, Meyer RA, Belzberg AJ: Neuropathic pain after C7 spinal nerve transection in man. Pain 96:41-47, 2002

3. Allieu Y, Privat JM, Bonnel F: [Neurotization with the spinal nerve (nervus accessorius) in avulsions of roots of the brachial plexus.] Neurochirurgie 28:115-120, 1982 (Fre)

4. Allieu Y, Privat JM, Bonnel F: Paralysis in root avulsion of the brachial plexus: neurotization by the spinal accessory nerve, in Terzis JK (ed): Microreconstruction of Nerve Injuries. Philadelphia: WB Saunders, 1987, pp 415-423

5. Alnot JY, Jolly A, Frot B: [Direct treatment of nerve lesions in brachial plexus injuries in adults - a series of 100 operated cases.] Int Orthop 5:151-168, 1981

6. Arai H, Sato K, Yanai A: Hemihypoglossal-facial nerve anastomosis in treating unilateral facial palsy after acoustic neurinoma resection. J Neurosurg 82:51-54, 1995

7. Asfazadourian H, Tramond B, Dauge MC, et al: Morphometric study of the upper intercostal nerves: practical application for neurotizations in traumatic brachial plexus palsies. Chir Main 18:243-253, 1999

8. Aszmann OC, Rab M, Kamolz L, et al: The anatomy of the pectoral nerves and their significance in brachial plexus reconstruction. J Hand Surg Am 25:942-947, 2000

9. Balakrishnan G, Kadadi BK: Clinical examination versus routine and paraspinal electromyographic studies in predicting the site of lesion in brachial plexus injury. J Hand Surg Am 29: 140-143, 2004

10. Baliarsing AS, Doi K, Hattori Y: Bilateral elbow flexion reconstruction with functioning free muscle transfer for obstetric brachial plexus palsy. J Hand Surg Br 27:484-486, 2002

11. Bertelli JA, Ghizoni MF: Reconstruction of C5 and C6 brachial plexus avulsion injury by multiple nerve transfers: spinal accessory to suprascapular, ulnar fascicles to biceps branch, and triceps long or lateral head branch to axillary nerve. J Hand Surg Am 29:131-139, 2004

12. Blaauw G, Slooff AC: Transfer of pectoral nerves to the mus- 
culocutaneous nerve in obstetric upper brachial plexus palsy. Neurosurgery 53:338-342, 2003

13. Brandt KE, Mackinnon SE: A technique for maximizing biceps recovery in brachial plexus reconstruction. J Hand Surg Am 18:726-733, 1993

14. Brunelli G, Monini L: Neurotization of avulsed roots of brachial plexus by means of anterior nerves of cervical plexus. Clin Plast Surg 11:149-152, 1984

15. Burkholder LM, Houlden DA, Midha R, et al: Neurogenic motor evoked potentials: role in brachial plexus surgery. Case report. J Neurosurg 98:607-610, 2003

16. Carvalho GA, Nikkhah G, Matthies C, et al: Diagnosis of root avulsions in traumatic brachial plexus injuries: value of computerized tomography myelography and magnetic resonance imaging. J Neurosurg 86:69-76, 1997

17. Chuang DC: Neurotization procedures for brachial plexus injuries. Hand Clin 11:633-645, 1995

18. Chuang DC, Cheng SL, Wei FC, et al: Clinical evaluation of C7 spinal nerve transection: 21 patients with at least 2 years' follow-up. Br J Plast Surg 51:285-290, 1998

19. Chuang DC, Lee GW, Hashem F, et al: Restoration of shoulder abduction by nerve transfer in avulsed brachial plexus injury: evaluation of 99 patients with various nerve transfers. Plast Reconstr Surg 96:122-128, 1995

20. Chuang DC, Wei FC, Noordhoff MS: Cross-chest C7 nerve grafting followed by free muscle transplantations for the treatment of total avulsed brachial plexus injuries: a preliminary report. Plast Reconstr Surg 92:717-725, 1993

21. Chung DC, Carver N, Wei FC: Results of functioning free muscle transplantation for elbow flexion. J Hand Surg Am 21:1071-1077, 1996

22. Cusimano MD, Sekhar L: Partial hypoglossal to facial nerve anastomosis for reinnervation of the paralyzed face in patients with lower cranial nerve palsies: technical note. Neurosurgery 35:532-534, 1994

23. Doi K, Sakai K, Kuwata N, et al: Double free-muscle transfer to restore prehension following complete brachial plexus avulsion. J Hand Surg Am 20:408-414, 1995

24. Dolenc VV: Intercostal neurotization of the peripheral nerves in avulsion plexus injuries. Clin Plast Surg 11:143-147, 1984

25. Dubuisson AS, Kline DG: Brachial plexus injury: a survey of 100 consecutive cases from a single service. Neurosurgery 51:673-683, 2002

26. El-Gammal TA, Fathi NA: Outcomes of surgical treatment of brachial plexus injuries using nerve grafting and nerve transfers. J Reconstr Microsurg 18:7-15, 2002

27. Erb W: Ueber eine eigenthümliche Localisation von Lähmungen im Plexus brachialis. Verhandl Naturhist Med 2: 130-136, 1874

28. Ferraresi S, Garozzo D, Ravenni R, et al: Hemihypoglossal nerve transfer in brachial plexus repair: technique and results. Neurosurgery 50:332-335, 2002

29. Friedman AH, Nunley JA II, Goldner RD, et al: Nerve transposition for the restoration of elbow flexion following brachial plexus avulsion injuries. J Neurosurg 72:59-64, 1990

30. Fu SY, Gordon T: Contributing factors to poor functional recovery after delayed nerve repair: prolonged axotomy. J Neurosci 15:3876-3885, 1995

31. Fu SY, Gordon T: Contributing factors to poor functional recovery after delayed nerve repair: prolonged denervation. J Neurosci 15:3886-3895, 1995

32. Giddins GE, Kakkar N, Alltree J, et al: The effect of unilateral intercostal nerve transfer upon lung function. J Hand Surg Br 20:675-676, 1995

33. Gilbert A: Long-term evaluation of brachial plexus surgery in obstetrical palsy. Hand Clin 11:583-595, 1995

34. Gilbert A, Whitaker I: Obstetrical brachial plexus lesions. J Hand Surg Br 16:489-491, 1991

35. Gu Y, Xu J, Chen L, et al: Long term outcome of contralater- al C7 transfer: a report of 32 cases. Chin Med J 115:866-868, 2002

36. Gu YD, Cai PQ, Xu F, et al: Clinical application of ipsilateral C7 nerve root transfer for treatment of C5 and C6 avulsion of brachial plexus. Microsurgery 23:105-108, 2003

37. Gu YD, Chen DS, Zhang GM, et al: Long-term functional results of contralateral C7 transfer. J Reconstr Microsurg 14:57-59, 1998

38. Gutowski KA, Orenstein HH: Restoration of elbow flexion after brachial plexus injury: the role of nerve and muscle transfers. Plast Reconstr Surg 106:1348-1359, 2000

39. Hansasuta A, Tubbs RS, Grabb PA: Surgical relationship of the medial pectoral nerve to the musculocutaneous nerve: a cadaveric study. Neurosurgery 48:203-207, 2001

40. Hattori Y, Doi K, Fuchigami Y, et al: Experimental study on donor nerves for brachial plexus injury: comparison between the spinal accessory nerve and the intercostal nerve. Plast Reconstr Surg 100:900-906, 1997

41. Hattori Y, Doi K, Toh S, et al: Surgical approach to the spinal accessory nerve for brachial plexus reconstruction. J Hand Surg Am 26:1073-1076, 2001

42. Holland NR, Belzberg AJ: Intraoperative electrodiagnostic testing during cross-chest C7 nerve root transfer. Muscle Nerve 20:903-905, 1997

43. Hou Z, Xu Z: Nerve transfer for treatment of brachial plexus injury: comparison study between the transfer of partial median and ulnar nerves and that of phrenic and spinal accessary nerves. Chin J Traumatol 5:263-266, 2002

44. Kawabata H, Shibata T, Matsui Y, et al: Use of intercostal nerves for neurotization of the musculocutaneous nerve in infants with birth-related brachial plexus palsy. J Neurosurg 94:386-391, 2001

45. Kawai H, Kawabata H, Masada K, et al: Nerve repairs for traumatic brachial plexus palsy with root avulsion. Clin Orthop 237:75-86, 1988

46. Kierner AC, Zelenka I, Heller S, et al: Surgical anatomy of the spinal accessory nerve and the trapezius branches of the cervical plexus. Arch Surg 135:1428-1431, 2000

47. Kim DH, Cho YJ, Tiel RL, et al: Outcomes of surgery in 1019 brachial plexus lesions treated at Louisiana State University Health Sciences Center. J Neurosurg 98:1005-1016, 2003

48. Kline DG: Perspective concerning brachial plexus injury and repair. Neurosurg Clin N Am 2:151-164, 1991

49. Kline DG, Happel LT: Penfield Lecture. A quarter century's experience with intraoperative nerve action potential recording. Can J Neurol Sci 20:3-10, 1993

50. Kline DG, Hudson AR: Nerve Injuries: Operative Results for Major Nerve Injuries, Entrapments, and Tumors. Philadelphia: WB Saunders, 1995

51. Kline DG, Nulsen FE: The neuroma in continuity. Its preoperative and operative management. Surg Clin North Am 52: 1189-1209, 1972

52. Leechavengvongs $\mathrm{S}$, Witoonchart $\mathrm{K}$, Uerpairojkit $\mathrm{C}$, et al: Nerve transfer to biceps muscle using a part of the ulnar nerve in brachial plexus injury (upper arm type): a report of 32 cases. J Hand Surg Am 23:711-716, 1998

53. Leechavengvongs S, Witoonchart $\mathrm{K}$, Uerpairojkit $\mathrm{C}$, et al: Nerve transfer to deltoid muscle using the nerve to the long head of the triceps, part II: a report of 7 cases. J Hand Surg Am 28:633-638, 2003

54. Loy S, Bhatia A, Asfazadourian H, et al: [Ulnar nerve fascicle transfer onto to the biceps muscle nerve in C5-C6 or C5C6-C7 avulsions of the brachial plexus. Eighteen cases.] Ann Chir Main Memb Super 16:275-284, 1997 (Fre)

55. Luedemann W, Hamm M, Blomer U, et al: Brachial plexus neurotization with donor phrenic nerves and its effect on pulmonary function. J Neurosurg 96:523-526, 2002

56. Malessy MJ, Bakker D, Dekker AJ, et al: Functional magnetic resonance imaging and control over the biceps muscle after 
intercostal-musculocutaneous nerve transfer. J Neurosurg 98:261-268, 2003

57. Malessy MJ, Hoffmann CF, Thomeer RT: Initial report on the limited value of hypoglossal nerve transfer to treat brachial plexus root avulsions. J Neurosurg 91:601-604, 1999

58. Malessy MJ, Thomeer RT: Evaluation of intercostal to musculocutaneous nerve transfer in reconstructive brachial plexus surgery. J Neurosurg 88:266-271, 1998

59. Malessy MJ, Thomeer RT, van Dijk JG: Changing central nervous system control following intercostal nerve transfer. J Neurosurg 89:568-574, 1998

60. Malessy MJ, van der Kamp W, Thomeer RT, et al: Cortical excitability of the biceps muscle after intercostal-to-musculocutaneous nerve transfer. Neurosurgery 42:787-795, 1998

61. Malessy MJ, van Duinen SG, Feirabend HK, et al: Correlation between histopathological findings in C-5 and C-6 nerve stumps and motor recovery following nerve grafting for repair of brachial plexus injury. J Neurosurg 91:636-644, 1999

62. Mano Y, Nakamuro T, Tamura R, et al: Central motor reorganization after anastomosis of the musculocutaneous and intercostal nerves following cervical root avulsion. Ann Neurol 38:15-20, 1995

63. Mcguiness CN, Kay SP: The prespinal route in contralateral C7 nerve root transfer for brachial plexus avulsion injuries. J Hand Surg Br 27:159-160, 2002

64. Merrell GA, Barrie KA, Katz DL, et al: Results of nerve transfer techniques for restoration of shoulder and elbow function in the context of a meta-analysis of the English literature. J Hand Surg Am 26:303-314, 2001

65. Midha R: Epidemiology of brachial plexus injuries in a multitrauma population. Neurosurgery 40:1182-1189, 1997

66. Midha R, Kline DG: Evaluation of the neuroma in continuity, in Omer GE Jr, Spinner M, Van Beek AL (eds): Management of Peripheral Nerve Problems, ed 2. Philadelphia: WB Saunders, 1998, pp 319-327

67. Millesi H: Brachial plexus injuries. Management and results. Clin Plast Surg 11:115-120, 1984

68. Minami M, Ishii S: Satisfactory elbow flexion in complete (preganglionic) brachial plexus injuries: produced by suture of third and fourth intercostal nerves to musculocutaneous nerve. J Hand Surg Am 12:1114-1118, 1987

69. Nagano A, Yamamoto S, Mikami Y: Intercostal nerve transfer to restore upper extremity functions after brachial plexus injury. Ann Acad Med Singapore 24 (Suppl 4):42-45, 1995

70. Narakas AO: Thoughts on neurotization or nerve transfers in irreparable nerve lesions. Clin Plast Surg 11:153-159, 1984

71. Narakas AO, Hentz VR: Neurotization in brachial plexus injuries. Indication and results. Clin Orthop 237:43-56, 1988

72. Nath RK, Mackinnon SE, Shenaq SM: New nerve transfers following peripheral nerve injuries. Oper Techn Plast Reconstr Surg 4:2-11, 1997

73. Oberle J, Antoniadis G, Kast E, et al: Evaluation of traumatic cervical nerve root injuries by intraoperative evoked potentials. Neurosurgery 51:1182-1190, 2002

74. Oberlin C, Beal D, Leechavengvongs S, et al: Nerve transfer to biceps muscle using a part of ulnar nerve for C5-C6 avulsion of the brachial plexus: anatomical study and report of four cases. J Hand Surg Am 19:232-237, 1994

75. Pitty LF, Tator CH: Hypoglossal-facial nerve anastomosis for facial nerve palsy following surgery for cerebellopontine angle tumors. J Neurosurg 77:724-731, 1992

76. Ruch DS, Friedman A, Nunley JA: The restoration of elbow flexion with intercostal nerve transfers. Clin Orthop 314: 95-103, 1995

77. Samardzic M, Grujicic D, Antunovic V, et al: Reinnervation of avulsed brachial plexus using the spinal accessory nerve. Surg Neurol 33:7-11, 1990

78. Samardzic M, Grujicic D, Rasulic L, et al: Transfer of the medial pectoral nerve: myth or reality? Neurosurgery 50: 1277-1282, 2002
79. Samardzic M, Rasulic L, Grujicic D, et al: Results of nerve transfers to the musculocutaneous and axillary nerves. Neurosurgery 46:93-103, 2000

80. Samii A, Carvalho GA, Samii M: Brachial plexus injury: factors affecting functional outcome in spinal accessory nerve transfer for the restoration of elbow flexion. J Neurosurg 98: 307-312, 2003

81. Samii M, Carvalho GA, Nikkhah G, et al: Surgical reconstruction of the musculocutaneous nerve in traumatic brachial plexus injuries. J Neurosurg 87:881-886, 1997

82. Samii M, Matthies C: Management of 1000 vestibular schwannomas (acoustic neuromas): the facial nerve-preservation and restitution of function. Neurosurgery 40: 684-695, 1997

83. Sawamura Y, Abe H: Hypoglossal-facial nerve side-to-end anastomosis for preservation of hypoglossal function: results of delayed treatment with a new technique. J Neurosurg 86: 203-206, 1997

84. Seddon HJ: Surgical Disorders of the Peripheral Nerves. Edinburgh: Churchill Livingstone, 1972

85. Sedel L: The results of surgical repair of brachial plexus injuries. J Bone Joint Surg Br 64:54-66, 1982

86. Simesen K, Haase J: Microsurgery in brachial plexus lesions. Acta Orthop Scand 56:238-241, 1985

87. Solonen KA, Vastamaki M, Strom B: Surgery of the brachial plexus. Acta Orthop Scand 55:436-440, 1984

88. Songcharoen P: Brachial plexus injury in Thailand: a report of 520 cases. Microsurgery 16:35-39, 1995

89. Songcharoen P, Mahaisavariya B, Chotigavanich C: Spinal accessory neurotization for restoration of elbow flexion in avulsion injuries of the brachial plexus. J Hand Surg Am 21: 387-390, 1996

90. Songcharoen P, Wongtrakul S, Mahaisavariya B, et al: Hemicontralateral C7 transfer to median nerve in the treatment of root avulsion brachial plexus injury. J Hand Surg Am 26: 1058-1064, 2001

91. Sungpet A, Suphachatwong C, Kawinwonggowit V: One-fascicle median nerve transfer to biceps muscle in $\mathrm{C} 5$ and $\mathrm{C} 6$ root avulsions of brachial plexus injury. Microsurgery 23: 10-13, 2003

92. Sungpet A, Suphachatwong C, Kawinwonggowit V: Sensory abnormalities after the seventh cervical nerve root transfer. Microsurgery 19:287-288, 1999

93. Sungpet A, Suphachatwong C, Kawinwonggowit V: Surgical anatomy of bicipital branch of musculocutaneous nerve. J Med Assoc Thai 81:532-535, 1998

94. Sungpet A, Suphachatwong C, Kawinwonggowit V, et al: Transfer of a single fascicle from the ulnar nerve to the biceps muscle after avulsions of upper roots of the brachial plexus. $\mathbf{J}$ Hand Surg Br 25:325-328, 2000

95. Terzis JK, Papakonstantinou KC: The surgical treatment of brachial plexus injuries in adults. Plast Reconstr Surg 106: 1097-1124, 2000

96. Terzis JK, Vekris MD, Soucacos PN: Outcomes of brachial plexus reconstruction in 204 patients with devastating paralysis. Plast Reconstr Surg 104:1221-1240, 1999

97. Tiel RL, Happel LT Jr, Kline DG: Nerve action potential recording method and equipment. Neurosurgery 39:103-109, 1996

98. Tung TH, Mackinnon SE: Brachial plexus injuries. Clin Plast Surg 30:269-287, 2003

99. Tung TH, Novak CB, Mackinnon SE: Nerve transfers to the biceps and brachialis branches to improve elbow flexion strength after brachial plexus injuries. J Neurosurg 98: 313-318, 2003

100. Tuttle HK: Exposure of the brachial plexus with nerve transplantation. JAMA 61:15-17, 1913

101. Viterbo F, Franciosi LF, Palhares A: Nerve graftings and endto-side neurorrhaphies connecting the phrenic nerve to the brachial plexus. Plast Reconstr Surg 96:494-495, 1995 
102. Waikakul S, Orapin S, Vanadurongwan V: Clinical results of contralateral $\mathrm{C} 7$ root neurotization to the median nerve in brachial plexus injuries with total root avulsions. J Hand Surg Br 24:556-560, 1999

103. Waikakul S, Wongtragul S, Vanadurongwan V: Restoration of elbow flexion in brachial plexus avulsion injury: comparing spinal accessory nerve transfer with intercostal nerve transfer. J Hand Surg Am 24:571-577, 1999

104. Witoonchart K, Leechavengvongs S, Uerpairojkit C, et al: Nerve transfer to deltoid muscle using the nerve to the long head of the triceps, part I: an anatomic feasibility study. J Hand Surg Am 28:628-632, 2003

105. Yamada S, Lonser RR, Iacono RP, et al: Bypass coaptation procedures for cervical nerve root avulsion. Neurosurgery 38:1145-1152, 1996

106. Yamada S, Peterson GW, Soloniuk DS, et al: Coaptation of the anterior rami of C-3 and C-4 to the upper trunk of the brachial plexus for cervical nerve root avulsion. J Neurosurg 74: 171-177, 1991

107. Yu ZJ, Sui S, Yu S, et al: Contralateral normal C7 nerve transfer after upper arm shortening for the treatment of total root avulsion of the brachial plexus: a preliminary report. Plast Reconstr Surg 111:1465-1469, 2003

Manuscript received March 15, 2004.

Accepted in final form April 2, 2004.

Address reprint requests to: Rajiv Midha, M.D., Division of Neurosurgery, Department of Surgery, Sunnybrook and Women's College Health Sciences Centre, University of Toronto, 2075 Bayview Avenue, Toronto, ON M4N 3M5, Canada. email: rajiv.midha@sw.ca. 